\title{
Embolization of a Complex Posterior Fossa Dural Arteriovenous Fistula with Precipitating Hydrophobic Injectable Liquid
}

Sir,

The angioarchitecture of intracranial dural arteriovenous fistulas (DAVFs) can vary widely, from lesions with a single fistulous connection to those with multiple sites of arteriovenous shunting. ${ }^{[1]}$ Endovascular treatment is currently the first-line intervention in the management of intracranial DAVFs. A number of embolic agents have been employed for the treatment of DAVFs. Precipitating hydrophobic injectable liquid (PHIL; MicroVention, Tustin, California, USA) is a novel permanent liquid embolic agent which may allow better intravascular penetration than ethylene vinyl alcohol copolymer (Onyx; ev3 Neurovascular, Irvine, California, USA). ${ }^{[2]}$ However, the literature regarding the use of PHIL for the treatment of intracranial vascular malformations is presently very limited. ${ }^{[2-4]} \mathrm{We}$ describe a case of a patient with a complex posterior fossa DAVF which was successfully embolized with PHIL.

A 73-year-old male presented with 2 weeks of recurrent syncope. Computed tomography angiography showed an infratentorial vascular malformation located posterior to the pineal gland and above the vermis of the cerebellum draining into the straight sinus [Figure 1a and b]. Further evaluation with cerebral angiography revealed a Borden

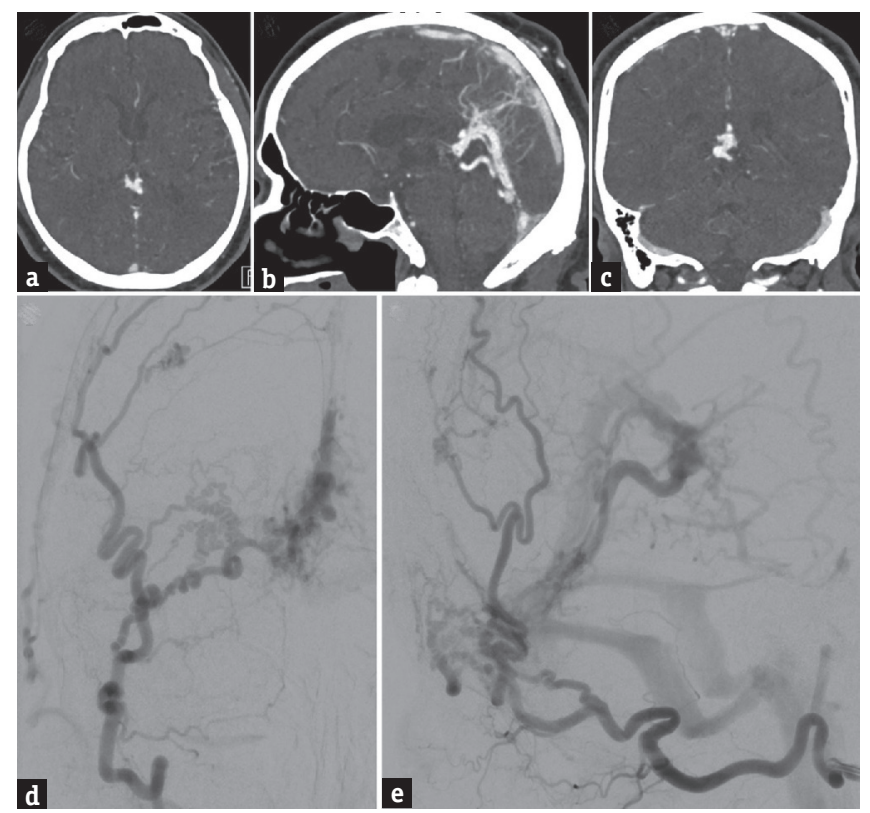

Figure 1: Brain computed tomography angiography, (a) axial, (b) sagittal, and (c) coronal views, shows a vascular malformation located posterior to the pineal gland with multiple dural arterial feeders and drainage into the straight sinus. Cerebral angiography, (d) anteroposterior and (e) lateral views of a right external carotid artery injection, shows a dural arteriovenous fistula supplied by multiple external carotid artery branches, which converge at a dural branch coursing in the falx toward the primary site of arteriovenous shunting, in the region of the superior vermian vein. The dural arteriovenous fistula drains predominantly into the vein of Galen and straight sinus and results in cerebellar pial venous congestion
Type III, Cognard Type IV DAVF parasitizing blood supply from multiple branches of the right external carotid artery, including the middle meningeal, superficial temporal, and occipital arteries, as well as the artery of the falx cerebri and left posterior cerebral artery [Figure $1 \mathrm{c}-\mathrm{e}]$. There were two sites of the arteriovenous shunting: One into the vein of Galen (VOG) and straight sinus which comprised the majority of the DAVF's venous drainage and another directly into the superior vermian vein. The shunting from the DAVF was also resulting in pial venous congestion at the surface of the cerebellum.

The patient underwent transarterial embolization of the DAVF using PHIL [Figure 2]. The fistulous connection draining into the VOG was occluded from the right middle meningeal artery. However, the straight sinus was inadvertently occluded during this stage of the embolization. The fistulous connection draining into the superior vermian vein was occluded from the right occipital artery. Overall, seven injections of PHIL performed utilizing a total of $1 \mathrm{~mL}$ of $30 \%$ PHIL and $6 \mathrm{~mL}$ of $25 \%$ PHIL. The final postembolization angiography demonstrated no evidence of residual arteriovenous shunting, with resolution of the preoperative cerebellar venous congestion. Due to the iatrogenic straight sinus thrombosis, the patient was administered an intravenous heparin infusion for $48 \mathrm{~h}$ after the procedure, with the goal of maintaining a therapeutic partial thromboplastin time of 50-70 s. The patient had an uncomplicated postoperative course and was discharged 4 days after the embolization procedure with 1 month of therapeutic enoxaparin. Follow-up angiography 7 months after embolization [Figure 3] showed durable occlusion of the DAVF. In addition, the patient's preoperative syncope resolved at 2 months follow-up, and he remained asymptomatic at 7 months clinical follow-up.

The management of DAVFs is multimodal, comprising embolization, surgical ligation, and stereotactic radiosurgery. ${ }^{[1,4,5]}$ Since PHIL is a relatively new embolic agent, data regarding its outcomes are sparse. Leyon et al. treated five intracranial and three spinal DAVFs with PHIL as the sole embolic agent and achieved complete occlusion in seven patients $(88 \%){ }^{[4]}$ There were no cases of technical or clinical complications. Samaniego et al. embolized five brain arteriovenous malformation (AVM) patients with PHIL, either as the sole embolic agent or in conjunction with Onyx. ${ }^{[3]}$ The Spetzler-Martin grades were III in three AVMs and II and IV each in one AVM. A total of nine arterial pedicles were embolized with PHIL, and curative embolization was achieved in three AVMs (60\%), including one Grade II and two Grade III lesions. There were no procedural complications. Koçer et al. used PHIL to embolize three brain AVMs before resection. ${ }^{[2]}$ On histopathological analysis, PHIL elicited 


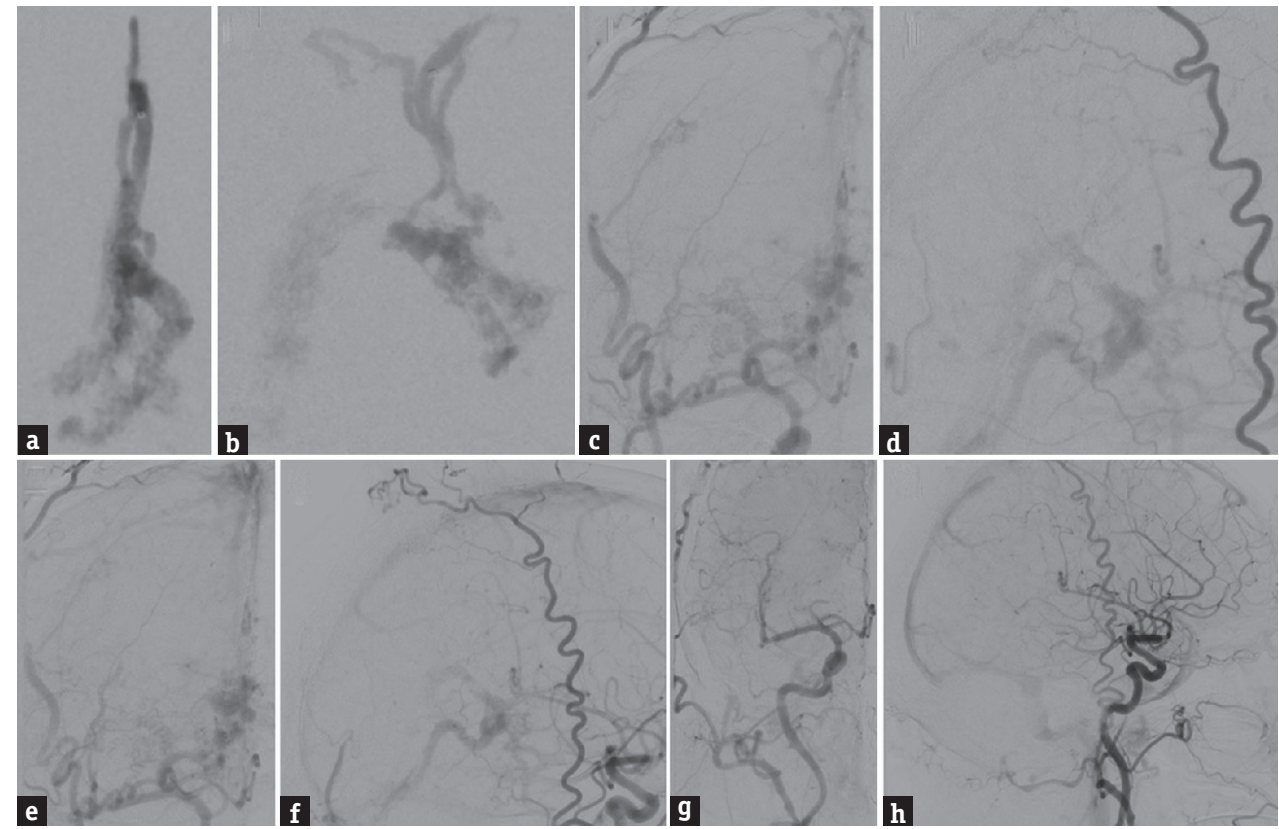

Figure 2: Cerebral angiography during the embolization procedure using precipitating hydrophobic injectable liquid. (a) Anteroposterior and (b) lateral views of a right middle meningeal artery injection, after $1 \mathrm{~mL}$ of $30 \%$ precipitating hydrophobic injectable liquid was injected (injection 1/7). (c) Anteroposterior and (d) lateral views of a right external carotid artery injection, after another $1 \mathrm{~mL}$ of $25 \%$ precipitating hydrophobic injectable liquid was injected (injection $2 / 7$ ). (e) Anteroposterior and (f) lateral views of a right external carotid artery injection, after another $1 \mathrm{~mL}$ of $25 \%$ precipitating hydrophobic injectable liquid was injected (injection $3 / 7$ ). The final angiography after a total of 7 precipitating hydrophobic injectable liquid injections ( $1 \mathrm{~mL}$ of $30 \%$ precipitating hydrophobic injectable liquid and $6 \mathrm{~mL}$ of $25 \%$ precipitating hydrophobic injectable liquid), (g) anteroposterior and (h) lateral views of a right common carotid artery injection, shows complete obliteration of the dural arteriovenous fistula

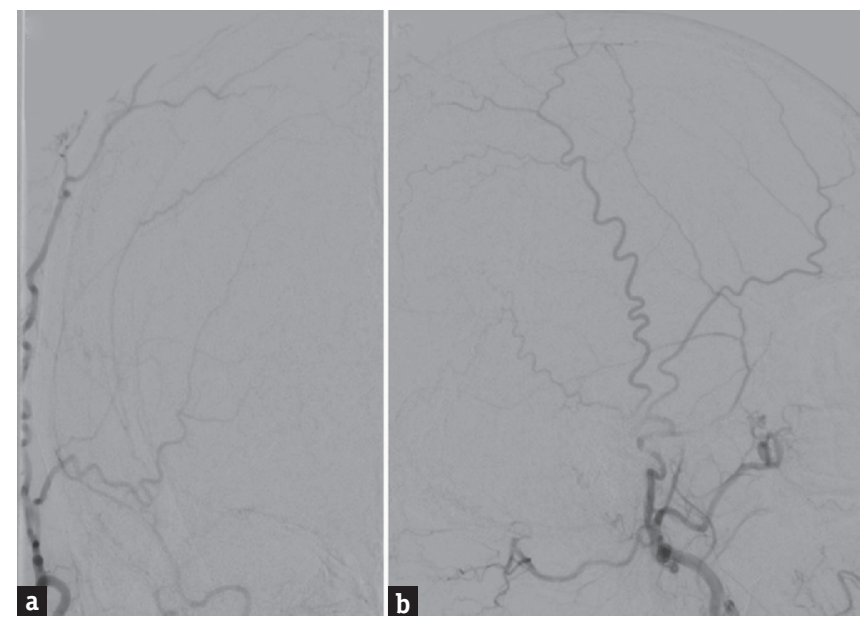

Figure 3: Cerebral angiography performed 7 months after precipitating hydrophobic injectable liquid embolization, (a) anteroposterior and (b) lateral views of a right external carotid artery injection, shows no evidence of residual or recurrent arteriovenous shunting

moderate inflammatory changes in the embolized vessels without angionecrosis, compared to Onyx, which elicited a milder inflammatory reaction with angionecrosis. The caliber of the smallest vessels containing PHIL versus Onyx was 2.9 and $5 \mu \mathrm{m}$, respectively. This suggests PHIL may penetrate vascular malformations more deeply than Onyx, thereby affording an advantage for the embolization of some lesions.

We were able to successfully obliterate a complex posterior fossa DAVF with PHIL in a single embolization procedure.
The procedure was complicated by straight sinus thrombosis, which did not cause clinical sequelae. The patient's preoperative symptoms also resolved after DAVF occlusion, indicating an association among the DAVF, its associated cerebellar pial venous congestion, and the patient's syncopal episodes. Our case serves to add to the paucity of data regarding PHIL for embolization of intracranial vascular malformations. Additional studies from larger patient cohorts with long-term angiographic and clinical follow-up are necessary to better define the role of PHIL in the endovascular management of DAVFs.

\section{Financial support and sponsorship}

Nil.

\section{Conflicts of interest}

There are no conflicts of interest.

\section{Dale Ding ${ }^{1,2}$, Ben McGuinness ${ }^{3}$, Stefan Brew ${ }^{3}$}

${ }^{1}$ Department of Neurosurgery, University of Virginia, Charlottesville, VA 22908, USA, Departments of ${ }^{2}$ Neurosurgery and ${ }^{3}$ Radiology, Auckland City Hospital, Auckland 1142,

New Zealand

Address for correspondence: Dr. Dale Ding, Department of Neurosurgery, University of Virginia,

P. O. Box: 800212, Charlottesville, VA 22908, USA. E-mail: dmd7q@hscmail.mcc.virginia.edu

\section{REFERENCES}

1. Awad IA, Little JR, Akarawi WP, Ahl J. Intracranial dural arteriovenous malformations: Factors predisposing to an 
aggressive neurological course. J Neurosurg 1990;72:839-50.

2. Koçer N, Hanimoglu H, Batur S, Kandemirli SG, Kizilkiliç O, Sanus Z, et al. Preliminary experience with precipitating hydrophobic injectable liquid in brain arteriovenous malformations. Diagn Interv Radiol 2016;22:184-9.

3. Samaniego EA, Kalousek V, Abdo G, Ortega-Gutierrez S. Preliminary experience with precipitating hydrophobic injectable liquid (PHIL) in treating cerebral AVMs. J Neurointerv Surg 2016. pii: Neurintsurg-2015-012210.

4. Leyon JJ, Chavda S, Thomas A, Lamin S. Preliminary experience with the liquid embolic material agent PHIL (precipitating hydrophobic injectable liquid) in treating cranial and spinal dural arteriovenous fistulas: Technical note. J Neurointerv Surg 2016;8:596-602.

5. Chen CJ, Lee CC, Ding D, Starke RM, Chivukula S, Yen CP, et al. Stereotactic radiosurgery for intracranial dural arteriovenous fistulas: Asystematic review. J Neurosurg 2015;122:353-62.
This is an open access article distributed under the terms of the Creative Commons Attribution-NonCommercial-ShareAlike 3.0 License, which allows others to remix, tweak, and build upon the work non-commercially, as long as the author is credited and the new creations are licensed under the identical terms.

\begin{tabular}{|l|l|}
\hline \multicolumn{2}{|c|}{ Access this article online } \\
\hline Quick Response Code: & Website: \\
\hline
\end{tabular}

How to cite this article: Ding D, McGuinness B, Brew S. Embolization of a complex posterior fossa dural arteriovenous fistula with precipitating hydrophobic injectable liquid. J Neurosci Rural Pract 2016;7:S135-7. 